\title{
$\begin{array}{ll}\text { Research Square } & \begin{array}{l}\text { Preprints are preliminary reports that have not undergone peer review. } \\ \text { They should not be considered conclusive, used to inform clinical practice, } \\ \text { or referenced by the media as validated information. }\end{array}\end{array}$
}

\section{Worldwide Patterns in Alzheimer's Disease and other Dementias Prevalence from 1990 to 2017: A Growth Mixture Models Approach}

\author{
Nasrin Borumandnia \\ Shaheed Beheshti University of Medical Sciences \\ Hamid Alavi Majd ( $\sim$ alavimajd@gmail.com ) \\ Shaheed Beheshti University of Medical Sciences \\ Naghmeh Khadembashi \\ Shaheed Beheshti University of Medical Sciences \\ Keyvan Olazadeh \\ Shaheed Beheshti University of Medical Sciences \\ Hojat Alaii \\ Shaheed Beheshti University of Medical Sciences
}

\section{Research article}

Keywords: Alzheimer's disease and other dementias, Global Burden of Disease, Cluster Analysis.

Posted Date: May 11th, 2020

DOl: https://doi.org/10.21203/rs.3.rs-25512/v1

License: (1) This work is licensed under a Creative Commons Attribution 4.0 International License. Read Full License 


\section{Abstract}

Background This study was designed to monitor the longitudinal trends of Alzheimer's disease and other dementias (ADD) prevalence among world countries, as well as classifying them into clusters in which countries within each cluster have similar trends over time.

Methods The ADD prevalence in 195 countries during 1990-2017 were extracted from the Global Burden of Disease study's database. The Latent Growth Models (LGMs) and also Latent Growth Mixture models (LGMM) were applied for trend analysis.

Results The highest and the lowest increase in ADD were observed in Europe and Africa, respectively. Increase in ADD was higher in women. LGMM allocated Nordic Countries in the class with a downward trend with a downward trend, with rate of -11.5 in 100000 person in every 2 years. Japan alone entered a class with a dramatically sharp increase with rate of 185 in 100000 person in every 2 years, the highest rank in ADD trend. Most European and American countries were entered into classes with higher increasing trend, rate between 20.4 and 53.6 in 100000 person in every 2 years, relative to the most of Asian countries which were less likely to have the increase of ADD, with rate of 6.45 in 100000 person in every 2 years.

Conclusion A substantial difference was observed in ADD trend among the countries: the decline in Nordic countries, which could be due to "Health Care of the elderly in the Nordic Countries" program, and the highly differentiated ascending trend in Japan, which is not necessarily due to the aging population; none of other countries, which have elderly population too, witnessed such sharp increase in their ADD. The clarification of the cause of the last finding calls for more epidemiological studies.

\section{Background}

Today, Alzheimer's disease (AD) is at the forefront of biomedical research. According to the World Health Organization, by the year 2030 and 2050 , 74.7 million and 114 million people will suffer from AD, respectively. The estimated cost of care for these people is about 2 trillion dollars [1]. In addition, according to a meta-analysis study conducted in 2016 , for individuals over the age of 60 , the overall prevalence of AD is $40.19 \%$ across the world [2]. The 2015 World Alzheimer Report manifested that there existed 46.8 million people living with dementia worldwide, where the anticipated number of cases almost doubled every 20 years [3, 4].

Based on the meta-analysis performed over the prevalence of ADD among the elderly in Europe in 2017, the prevalence was estimated as 5.05\%, varying from 3\% in France (in 1999) to 11.67\% in Spain (in 1995) [5-7]. Based on the review in 2008 on developing countries in Asia, the reported ADD prevalence was as scattered as $2.7 \%$ in India (pooled over 1996-2006) and $21.1 \%$ in Israel (in 2002), and according the review in 2018 it was $15.75 \%$ in Japan [8-9]. The ADD prevalence in adults older than 50 years in Africa was also estimated to be about $2.4 \%$ in 2012 , varying from $2.3 \%$ in Nigeria to $5.93 \%$ in Egypt $[10,11]$. In a Delphi consensus study in 2005, the prevalence was estimated as $4.6 \%$ in Latin America and $6.4 \%$ in North America [12]. The 2019 Dementia Australia Prevalence Data reveals that an estimated 447,115 people living with all forms of dementia [13]. As these statistics showed, in all of the countries around the world, there is no single 'epidemic'; each country faces a different situation and there are great variations within different continents. In addition, these epidemics have been changed during the past decades. Therefore, it is necessary to investigate every continent separately and determine clusters of countries with similar trends of prevalence rates of Alzheimer's disease and other dementias (ADD) over time. The surveys over this topic performed by other researchers have been mostly regional and continental, rather than surveys over all countries across the world. So, as the main goal, we conducted this study in order to identify the trend of $A D$ rates in all continents during 1990-2017, using data from the Global Burden of Disease study's (GBD) database.

\section{Methods \\ Data Source}

Data for prevalence of ADD (rate in 100000 persons) in 195 countries and regions for male and female, from 1990 to 2017, were derived from GBD study which is freely available to the world's researchers and policymakers. All global, and regional estimates of the burden of diseases, injuries, and risk factors can be downloaded from current GBD data visualizations and the Global Health Data Exchange (GHDx).More details about the GBD study and the data is available [14]. The GBD is viewed as the most extensive worldwide observational epidemiological study thus far, describing mortality and morbidity from major diseases, injuries and risk factors to health at global, national and regional levels.

At first, all countries designated by GBD Study in six regions were considered, including: Asia, Africa, North American, South America, Europe and Australia \& Oceania. The trend of prevalence rates of ADD in each region were estimated, separately for males and females. Then, all countries were classified into subgroups with similar trends of ADD over the years.

Statistical analysis was performed using M-plus software, version 6.12 and also IBM SPSS statistics for windows, version 25.0. The institution of IRB was Shahid Beheshti University of Medical Sciences. Ethical approval number is IR.SBMU.RETECH.REC.1398.099.

\section{Statistical analysis}

\section{Analysis of Trends}


Among the longitudinal analytical methods, Latent Growth Models (LGMs) can handle the trend of longitudinal data. LGMs examine the trend of response variables over time. This approach is pertinent to various scales of response variables. In the present study, this modeling was applied for the purpose of investigating the trend of ADD prevalence in 195 countries across the continents; the response variable was the prevalence of ADD rate in each country across different continents during 1990 to 2017 (every 5 years). Considering the small number of countries in some regions, for reliable statistical modelling, the prevalence in every 5 years were used, instead of the prevalence of all years. Using Latent Growth models, the ADD pattern has been speculated separately for males and females. Two parameters of intercept and slope, estimated by this statistical modelling, are used for clinical interpretation; where intercept represents the estimated overall mean level of the initial outcome (in this study: initial prevalence of $A D D$ in the region in 1990), and slope is the average rate of outcome change (in this study: average rate of ADD prevalence in the region within every 5 years) over time [15]. It seems essential to note that LGM assumes all cases have the similar trend over time.

\section{Clustering Of Countries Based On Different Trends}

Latent Growth Mixture modeling (LGMM), generalized of LGM, refers to statistical approaches, representing subpopulations where population membership is not initially recognized, but is inferred from the data. In other words, in the present study, each country has a different trend in its ADD rate during time. With the help of the aforementioned model, the world countries have been divided into some subgroups (or clusters), in a way that those countries with the similar trend during time have fallen into the same cluster. It is worth mentioning that the factors affecting the clustering of the countries are not only based on their similarity of the trend over time, but the onset of the disease at the beginning of the study period (1990). For mixture modeling used with the longitudinal data of this study, the continuous response variable is the prevalence of ADD in each country from 1990 to 2017 (every 2 years).

\section{Results}

The descriptive statistics including mean \pm SD of ADD rate as well as estimates from the LGM in sex regions are shown in Table 1 . 
Table 1

Alzheimer's disease and other dementias rates (per 100,000) as mean (SD) and estimates from the LGM by the regions for trend analysis. Data were extracted from the Global Burden of Disease study's (GBD) database [14].

\begin{tabular}{|c|c|c|c|c|c|c|c|c|}
\hline & & & & Years & & & & \\
\hline Region & Gender & 1990 & 1995 & 2000 & 2005 & 2010 & 2015 & LGM estimates \\
\hline \multirow[t]{4}{*}{ Asia } & \multirow[t]{2}{*}{ Male } & \multirow[t]{2}{*}{ 220.7(103) } & \multirow[t]{2}{*}{ 227.2(116.6) } & \multirow[t]{2}{*}{ 245.5(144.3) } & \multirow[t]{2}{*}{ 272.3(179.7) } & \multirow[t]{2}{*}{$305.9(239.8)$} & \multirow[t]{2}{*}{$343.8(284.5)$} & Intercept:207.8 \\
\hline & & & & & & & & Slope:21.53 \\
\hline & \multirow[t]{2}{*}{ Female } & \multirow[t]{2}{*}{$350.1(205.1)$} & \multirow[t]{2}{*}{$369.6(242.3)$} & \multirow[t]{2}{*}{ 397.3(294.3) } & \multirow[t]{2}{*}{ 439.5(357.2) } & \multirow[t]{2}{*}{$500(466.2)$} & \multirow[t]{2}{*}{$564.4(538.2)$} & Intercept:339.2 \\
\hline & & & & & & & & Slope:33.5 \\
\hline \multirow[t]{4}{*}{ Africa } & \multirow[t]{2}{*}{ Male } & \multirow[t]{2}{*}{$155.8(63)$} & \multirow[t]{2}{*}{$157.3(67)$} & \multirow[t]{2}{*}{ 153.88(71.5) } & \multirow[t]{2}{*}{ 152.5(79.2) } & \multirow[t]{2}{*}{ 154.7(90.3) } & \multirow[t]{2}{*}{ 161.1(104.4) } & Intercept:156.2 \\
\hline & & & & & & & & Slope: -0.63 \\
\hline & \multirow[t]{2}{*}{ Female } & \multirow[t]{2}{*}{ 203.8(108.1) } & \multirow[t]{2}{*}{ 209.4(116.8) } & \multirow[t]{2}{*}{$210.8(125.2)$} & \multirow[t]{2}{*}{$215.9(136.3)$} & \multirow[t]{2}{*}{ 224.2(150.6) } & \multirow[t]{2}{*}{ 237.6(168.3) } & Intercept:204 \\
\hline & & & & & & & & Slope:3.8 \\
\hline \multirow[t]{4}{*}{ Europe } & \multirow[t]{2}{*}{ Male } & $557.5(162.6)$ & $586.14(172)$ & 632.2(178.5) & 689.4(181.3) & 769.7(198.3) & $866(227)$ & Intercept:537 \\
\hline & & & & & & & & Slope:59.2 \\
\hline & Female & 1076.3(374.2) & 1142.3(390.2) & 1211.1(389.5) & 1291.9(380.9) & 1412(391.7) & $1547.5(425.4)$ & Intercept:1089 \\
\hline & & & & & & & & Slope:82 \\
\hline North & Male & $319(118.9)$ & $342.3(128)$ & $361.9(130.6)$ & $394.6(142.5)$ & $440.5(157.3)$ & 501.7(187.8) & Intercept:313.9 \\
\hline & & & & & & & & Slope:26.18 \\
\hline & Female & 453.2(225.8) & 484.7(247) & $503.6(239.4)$ & $542(252)$ & $595.9(266.8)$ & $664.6(300.7)$ & Intercept: 437.8 \\
\hline & & & & & & & & Slope:37.2 \\
\hline South & Male & 288(101.8) & $308.4(109.4)$ & 333.7(113.7) & 362.1(111.8) & $395.4(112.4)$ & $428.8(117.7)$ & Intercept:279.7 \\
\hline & & & & & & & & Slope:29.7 \\
\hline & Female & $397.6(209.5)$ & $430.5(232.5)$ & 469.6(249.3) & $515.3(254.1)$ & $565.9(260.4)$ & $615.9(270.5)$ & Intercept:381.9 \\
\hline & & & & & & & & Slope:49 \\
\hline Australia & Male & 205.7(117.3) & 217.5(129.6) & 229.3(148.5) & $246(164)$ & 269(181.2) & $301.6(205.2)$ & Intercept:203.3 \\
\hline Oceania & & & & & & & & Slope:14.18 \\
\hline & Female & $321.5(248.8)$ & $344.9(274.8)$ & $364.5(301.7)$ & 393.7(314.7) & $424.9(323.2)$ & $466.9(338)$ & Intercept:322.13 \\
\hline & & & & & & & & Slope:25.5 \\
\hline
\end{tabular}

The last column in Table 1 shows the estimated result from fitting the LGM to these data. Both the estimated intercepts and slopes can help us to know more about mortality trends in these regions. The intercepts represent the estimated overall mean level of the initial ADD rate and the slopes show the average rate of change in ADD rate over time within each region. A positive and negative slope reveal that the rate had an incremental and decremental trend over the period of time, respectively. For instance, the estimates for female in Europe (Intercept $=1089$, Slope $=82)$ state that the initial ADD prevalence rate in this region was 1089 (in 1990) and the prevalence rate has an incremental trend with a slope of 82 during 1990 to 2015 (within every 5 years). The highest and the lowest increase in ADD have been estimated in Europe and Africa, respectively. Overall, increase in $A D D$ rate was higher in women than in men.

The result of GMM in Table 2 shows the clustering of 195 countries based on their trend of ADD rate between 1990 up to 2016 (within every 2 years). Using this model, countries were classified into 7 classes with different prevalence intercepts and trends. Note that the GMM was examined through various number of classes and based on entropy statistics, BIC and also quality of classes, the model with 7 linear class was chosen (the linear class means that the trend has been linear across time). Quality of latent class membership classification was determined using the entropy statistics, 0.974 , which revealed a good quality of clustering. 
Table 2

Results of growth mixture model for clustering of countries based on their trend in Alzheimer's disease and other dementias rate along time.

\begin{tabular}{|c|c|c|}
\hline $\begin{array}{l}\text { Class: (number of } \\
\text { countries in } \\
\text { class) }\end{array}$ & $\begin{array}{l}\text { Coefficients } \\
\text { of GMM: } \\
\text { Intercept } \\
\text { Slop (p- } \\
\text { value) }\end{array}$ & Countries in each class \\
\hline 1: (10) & $\begin{array}{l}1072.7 \\
27^{\star}\end{array}$ & $\begin{array}{l}\text { Austria, Belgium, France, Germany, Italy, Luxembourg, Netherlands, Netherlands, Spain, Switzerland, United } \\
\text { Kingdom }\end{array}$ \\
\hline 2: (132) & $\begin{array}{l}202.1 \\
6.45^{\star}\end{array}$ & Other countries excepts those in the other classes. \\
\hline 3: (1) & $\begin{array}{l}526.7 \\
185.57^{\star}\end{array}$ & Japan \\
\hline 4: (18) & $\begin{array}{l}597.35 \\
53.6^{\star}\end{array}$ & $\begin{array}{l}\text { Bermuda, Bulgaria, Croatia, Cuba, Estonia, Georgia, Greece, Latvia, Lithuania, Malta, Moldova, Montenegro, } \\
\text { Poland, Portugal, Puerto Rico, Romania, Serbia, Slovenia }\end{array}$ \\
\hline 5: (3) & $\begin{array}{l}1320.7 \\
-11.5^{\star}\end{array}$ & Denmark, Norway, Sweden \\
\hline 6: (21) & $\begin{array}{l}703.4 \\
20.4^{\star}\end{array}$ & $\begin{array}{l}\text { Andorra, Argentina, Australia, Barbados, Belarus, Canada, Cyprus, Czech Republic, Dominica, Finland, } \\
\text { Hungary, Iceland, Ireland, Israel, New Zealand, Russian, Seychelles, Slovakia, Ukraine, United States, Uruguay }\end{array}$ \\
\hline 7: (10) & $\begin{array}{l}242.8 \\
45.75^{\star}\end{array}$ & $\begin{array}{l}\text { Albania, Armenia, Bosnia and Herzegovina, China, Grenada, Macedonia, Northern Mariana, Islands, South } \\
\text { Korea, Taiwan, Thailand }\end{array}$ \\
\hline
\end{tabular}

As the slop coefficients in Table 2 shows, there are increasing trend in prevalence of ADD over time among countries in all classes, except for class 5. Yet, the amount of increasing rate is various in each class, such that the country in class 3 experienced the sharpest increase and countries in class 2 had the lowest increasing of Alzheimer's prevalence over time. The maps in Fig. 1 revealed the clusters of countries with estimated similar trend of ADD rates from 1990 up to 2016, in which the countries with similar trend are presented with the same color.

Imbalanced numbers of countries in classifications are not an unusual phenomenon in modeling and statistical analysis. As stated in the GMM model description, the clustering is based on two principles: first, the similarity of the ADD trend over time, and second, the relative similarity of the initial values of the ADD rate in countries within each cluster. To shed more light on this point, the growth trajectories within the 7 clusters are displayed in Fig. 2. Japan has an early prevalence rate and very different variations compared with other countries; Japan's prevalence of ADD has risen from around 600 in 1990 to 3,000 in 2016, while in the cluster of 132 countries, the initial prevalence rate was between 50 and 450 , with the largest increase in 2016 reaching to about 800 , varying considerably from Japan. In addition, it is important to note that the number of clusters and the quality of the clustering are determined using statistical criteria such as the entropy index and the Akaike information criterion. For this purpose, the model with different number of clusters and clustering types was studied and based on the best entropy index and Akaike information criterion, the model with 7 classes was selected as the final model.

\section{Discussion And Conclusions}

Every 3 seconds, someone in the world develops dementia and there is not a single epidemiology for it across the world. In the present study, the prevalence rates of Alzheimer among six geographic regions, including Asia, Africa, North America, South America, Europe and Australia \& Oceania showed a positive trend, with minimum and maximum ADD prevalence rate increases (on average) between 3.8 and 82 (rate in 100000 ) every 5 years in African and European female, respectively. The other regions also showed an increasing trend between these rates. The higher increase prevalence rate in Europe may be justified by reasons within which the rapid aging may be the most significant.

The present study monitored the trends in ADD prevalence rate among all of the mentioned countries, using the LGMM modeling. Based on this study's analysis, 195 countries and territories were clustered into 7 classes based on their trend of ADD during the 1990 to 2016 . According to the clusters, class 3, consisting of Japan, had a dramatically sharp increase from 1990 to 2016 in ADD rate. Fastest aging population may be the main reason for the large growth in the ADD prevalence trend in Japan. If aging is the influencing factor over this trend, according to the "World Atlas" report, Japan is expected to witness an increase in the growth rate of the old population from $27.2 \%$ in 2014 to $32.2 \%$ in 2030 . The consequences of 
this increase in Alzheimer's disease will turn into a serious issue in the near future. It's worth mentioning that though Japan has the oldest population of the world, and Italy and Portugal are in the second and third place after Japan, none of these countries witnessed such sharp increase in their ADD rate. That is why it is inferred that aging population alone cannot be the main factor for such ADD upsurge. Among all counties around the world, Japan with its exemplary technological advances and success allocated the most increasing trend of ADD to itself, which highlights the importance of strategies for early detection, diagnosis and treatment of ADD which should attract more and more attention. Such vivid soar in the results for Japan truly calls for much more attention and speculations.

Regarding the disease diagnosis in Japan, clinical practice for the administration of dementing diseases was established by six main societies in Japan including the Japanese Society of Psychiatry and Neurology, the Japan Society for Dementia Research, the Japanese Psychogeriatric Society, the Japan Geriatrics Society, the Japanese Society of Neurological Therapeutics, and the Japanese Society of Neurology. The guidelines outlined clinical signs, image findings, biochemical markers, and pharmacologic management guidance for ADD. The 2010 guidelines and practical strategies principally correspond to the US Alzheimer's Disease Management Council consensus for the management of ADD [16]. However, the manner in which diagnoses were made or how data was registered in Japan might be a potential reason for high statistics in comparison to other countries.

Denmark, Norway and Sweden (class 5) had a downward trend of 11.5 until 2016. This decreasing trend may be due to the promoting of strategies related to "Health and health care of the elderly in the Nordic Countries" program. For the purpose of maintaining a healthy diet, good health and good living conditions, together with active participation in social life, one powerful financial position seems crucial. Publicly-financed services such as high-cost protection medicines and health-care systems are often available in the Nordic region. According to the findings of the existing research, brain heath has a close relationship with heart and blood vessel health. Consequently, factors such as smoking, obesity, diabetes, and high cholesterol and high blood pressure in midlife which have a crucial role in causing cardiovascular diseases can be directly connected with a higher risk of developing Alzheimer and other dementias. Preventing cardiovascular diseases through reducing the risk of diabetes, high blood pressure, overweight, smoking and alcohol misuse are among the preventive strategies for dementia. It can be inferred that preventing cardiovascular diseases may lead to preventing dementia. Consequently, higher levels of education and better living conditions, prevention and treatment of cardiovascular diseases which reduces the risk of ADD are the main reasons for the reduction in the rates of ADD. More details are available in the report presented by the Nordic Medico-Statistical Committee [17].

Our results also showed that most of the countries and territories in Europe continent, as well as the United States were clustered in classes with increasing trend of ADD rate (classes 1,4 and 6), rising between 20.4 and 53.6. Most of Asian countries are clustered in class 4 , being less likely to increase the prevalence of Alzheimer's compared with other clusters, which include European and American countries. Of course, the differences in the diagnostic criteria used to diagnose dementia are also a likely source of variation in the prevalence of dementia among the reports.

Correspondingly, in developing countries like North America, Europe and Australia, the rates of ADD may be registered more accurately when compared with less developed countries such as many Asian ones.

The results of a meta-analysis study have shown that there is good evidence of a decline in the prevalence of Alzheimer's in high-income countries (where Japan is also excluded). Nevertheless, the mentioned paper has proposed the need for stronger and more comprehensive studies as to obtain accurate results regarding the Alzheimer's disease prevalence rate reduction in high-income countries, because this was not probable due to heterogeneity and given the large number of studies and the low sample size [18]. Lack of accurate and reliable data for ADD prevalence rate in some countries may be considered as a limitation of the present study. This limitation causes GBD to report the estimated prevalence rate for some diseases like ADD.

Among the risk factors of ADD, ageing, family history and genetics are the ones that can't be changed, but due to the growing trend of ADD in some countries, more programs are needed for the purpose of influencing the present crisis through general lifestyle. This program needs in-depth analysis in terms of socio-economic, medical or cultural changes.

\section{Abbreviations}

\section{ADD}

Alzheimer's disease and other Dementias

GBD

Global Burden of Disease

GHDx

Global Health Data Exchange

\section{LGM}

Latent Growth Models

LGMM

Latent Growth Mixture models 


\section{Declarations}

\section{Ethics approval and consent to participate}

This study was approved by Shahid Beheshti University of Medical Sciences. Owing to the using of IHME database, the requirement for informed consent was waived.

\section{Consent to publish}

We have used the Global Burden of Disease Study database and have cited according to the proposed format of the Institute for Health Metrics and Evaluation.

\section{Availability of data and materials}

Data is available from http://ghdx.healthdata.org/gbd-results-tool and is freely download.

\section{Competing Interests}

The authors have no conflict of interest to report.

\section{Funding}

No funding was received for this study.

\section{Authors' Contributions}

NB designed this study and participated in data extraction, data analysis, data interpretation and manuscript writing; HA participated in data analysis, data interpretation and manuscript writing; KO, HA participated in manuscript preparation and literature research. NK was responsible for, manuscript revising and editing. All authors approved the final version of the manuscript and agree to be accountable for all aspects of the work in ensuring the accuracy or integrity of the work.

\section{Acknowledgments}

The authors thank the Institute for Health Metrics and Evaluation (IHME) for providing the data.

\section{References}

1. Bhushan I, Kour M, Kour G, Gupta S, Sharma S, Yadav A. (2018) Alzheimer's disease: Causes \& treatment-A review.

2. Fiest KM, Roberts JI, Maxwell CJ, Hogan DB, Smith EE, Frolkis A, Cohen A, Kirk A, Pearson D, Pringsheim T. The prevalence and incidence of dementia due to Alzheimer's disease: a systematic review and meta-analysis. Can J Neurol Sci. 2016;43:51-82.

3. Reitz C, Mayeux R. Alzheimer disease: epidemiology, diagnostic criteria, risk factors and biomarkers. Biochem Pharmacol. 2014;88:640-51.

4. Prince M, Bryce R, Albanese E, Wimo A, Ribeiro W, Ferri CP. (2013) The global prevalence of dementia: a systematic review and metaanalysis. Alzheimer's \& dementia 9, 63-75. e62.

5. Niu H, Álvarez-Álvarez I, Guillén-Grima F, Aguinaga-Ontoso I. Prevalence and incidence of Alzheimer's disease in Europe: A meta-analysis. Neurología (English Edition). 2017 Oct 1;32(8):523 - 32.

6. Manubens J, Martinez-Lage J, Lacruz F, Muruzabal J, Larumbe R, Guarch C, Urrutia T, Sarrasqueta P, Martinez-Lage P, Rocca W. Prevalence of Alzheimer's disease and other dementing disorders in Pamplona. Spain Neuroepidemiology. 1995;14:155-64.

7. Salamon R, DARTIGUES J-F, NORDMANN R, PICHOT P, BLANCHER G, BOUREL M, RETHORE M-O, DE GENNES J-L, PELLERIN M, HILLEMAND M. (1999) Epidémiologie de la maladie d'Alzheimer: l'expérience Paquid. Discussion. Bulletin de l'Académie nationale de médecine 183, $129-142$.

8. Kalaria RN, Maestre GE, Arizaga R, Friedland RP, Galasko D, Hall K, Luchsinger JA, Ogunniyi A, Perry EK, Potocnik F. Alzheimer's disease and vascular dementia in developing countries: prevalence, management, and risk factors. Lancet Neurol. 2008;7:812-26.

9. 9.

10. Guerchet M, Mayston R, Lloyd-Sherlock P, Prince M, Aboderin I, Akinyemi R, Ezeah P. Dementia in sub-Saharan Africa: challenges and opportunities. London: Alzheimer's Disease International; 2017.

11. George-Carey R, Adeloye D, Chan KY, Paul A, Kolčić I, Campbell H, Rudan I. An estimate of the prevalence of dementia in Africa: a systematic analysis. Journal of global health. 2012 Dec;2(2).

12. Ferri CP, Prince M, Brayne C, Brodaty H, Fratiglioni L, Ganguli M, Hall K, Hasegawa K, Hendrie H, Huang Y. Global prevalence of dementia: a Delphi consensus study. The lancet. 2005;366:2112-7.

13. DIET AM. (2018) Mind games: approaches to staving off dementia. Mind. 
14. Global Burden of Disease Collaborative Network. Global Burden of Disease Study 2017. (GBD 2017) Results. Seattle, United States: Institute for Health Metrics and Evaluation (IHME), 2018. Available from http://ghdx.healthdata.org/gbd-results-tool.

15. Muthén L, Muthén B. (2019) Mplus. The comprehensive modelling program for applied researchers: user's guide 5.

16. 16 .

17. Nomesco N. (2017) Health and health care of the elderly in the Nordic Countries: From a statistical perspective.

18. Roehr S, Pabst A, Luck T, Riedel-Heller SG. Is dementia incidence declining in high-income countries? A systematic review and meta-analysis.

Clinical epidemiology. 2018;10:1233.

\section{Figures}

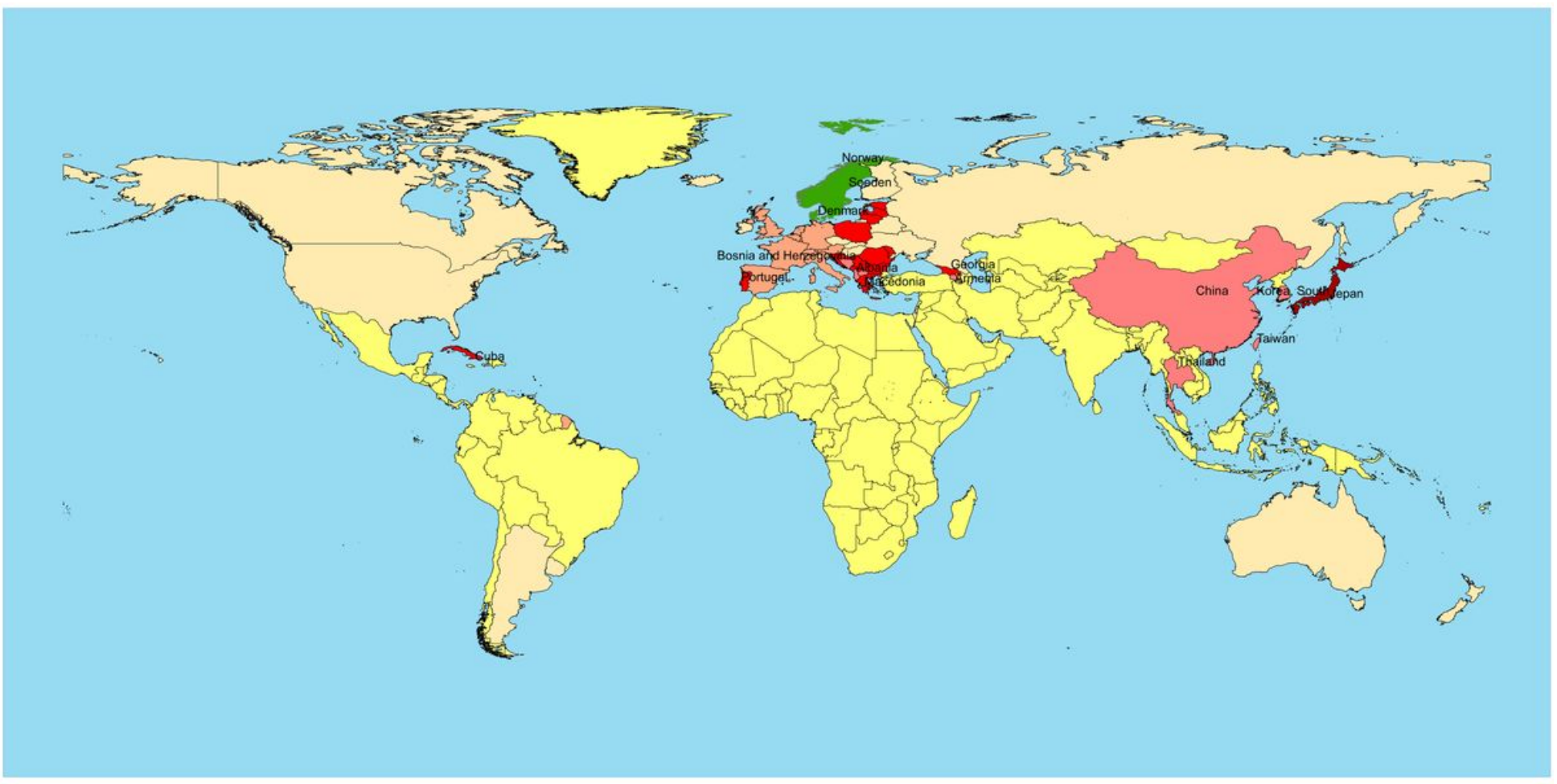

The average rate of alzheimer's deisease and other demantias prevalence change per 100,000 people

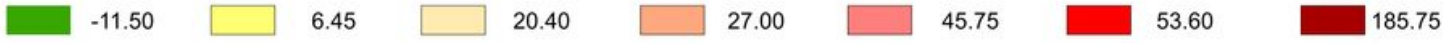

\section{Figure 1}

World's cluster map on the basis of Alzheimer's disease and other dementias' outbreak trends within the years 1990 to 2016 . This map shows the result of latent growth mixture model. Note: The designations employed and the presentation of the material on this map do not imply the expression of any opinion whatsoever on the part of Research Square concerning the legal status of any country, territory, city or area or of its authorities, or concerning the delimitation of its frontiers or boundaries. This map has been provided by the authors. 

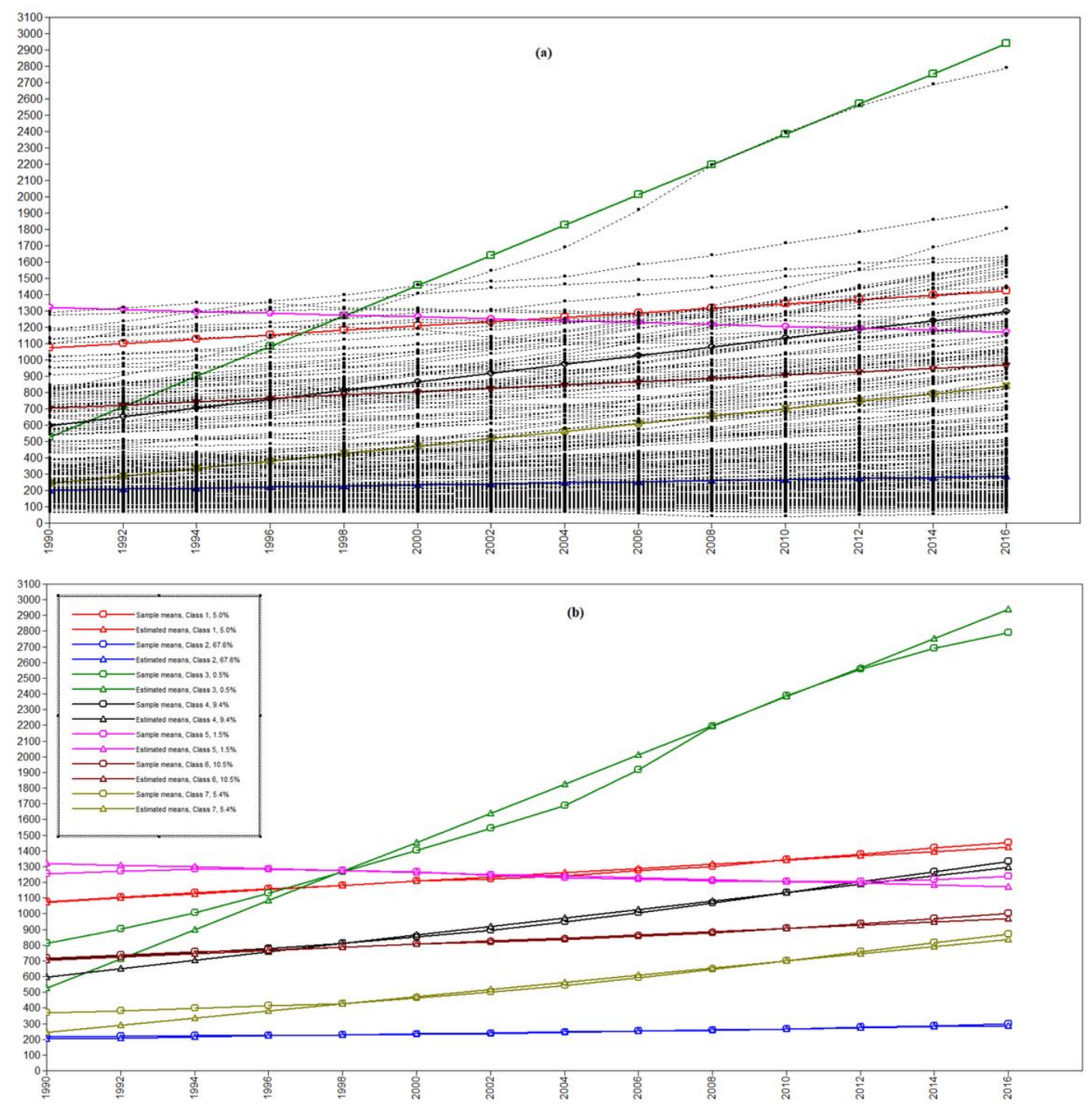

Figure 2

World's cluster map on the basis of Alzheimer's disease and other dementias' outbreak trends within the years 1990 to 2016. This map shows the result of latent growth mixture model. 